\title{
KINETICS OF PENTAAMMINE COBALT(III) COMPLEXES OF $\alpha$-HYDROXY ACIDS BY ISOQUINOLINIUM FLUOROCHROMATE IN MICELLAR MEDIUM
}

\author{
P. Rajkumar ${ }^{*}$, G.Saraswathy $^{2}$, Z. Abdul Vaheith ${ }^{3}$ and A. Fiaz Ahamed ${ }^{4}$ \\ ${ }^{1}$ Department of Chemistry, Priyadarshini Engineering College, \\ Vaniyambadi- 635751, (TamilNadu) India. \\ ${ }^{2}$ Department of Chemistry, Government College of Engineering, \\ Bargur- 635104, (TamilNadu) India. \\ ${ }^{3}$ Department of Chemistry, C.Abdul Hakeem College of Engineering \& Technology, \\ Vellore- 632509 (TamilNadu) India. \\ ${ }^{4} \mathrm{PG} \&$ Research Department of Chemistry, Islamiah College, \\ Vaniyambadi- 635752,(TamilNadu) India. \\ *E-mail: drprajkumar2014@gmail.com
}

\begin{abstract}
Kinetics of oxidation of Pentaamminecobalt (III) complexes of $\alpha$-hydroxy acids by Isoquinolinium Fluorochromate(IQFC) in micellar medium yielding nearly $100 \%$ of carbonyl compounds are ultimate products. This oxidation as a diagnostic tool to find out the fraction taking place by synchronous cleavages of $\mathrm{O}-\mathrm{H}$ and $\mathrm{C}-\mathrm{C}$ bonds. It has been set up that the rate of oxidation of Co(III) complexes of both bound and unbound $\alpha$-hydroxy acids are increased more in the presence of cationic micelle of Cetyltrimethylammonium bromide (CTAB), when compared to the anionic micelle of Sodium lauryl sulfate (NaLS). The 1 mole of cobalt(III) complexes of $\alpha$ hydroxy acids reacts with nearly 0.5 mole of Isoquinolinium Fluorochromate(IQFC), correspondingly 1 mole of $\alpha$ hydroxy acids reacts with nearly 1 mole of Isoquinolinium Fluorochromate(IQFC). The reaction goes by free radical mechanism was proved by acrylonitrile polymerization. The suitable methodology has been proposed.

Keywords: Pentaamminecobalt(III) Complexes, Isoquinolinium Fluorochromate(IQFC), Micelles, Oxidation, NaLS, CTAB.
\end{abstract}

(C) RASĀYAN. All rights reserved

\section{INTRODUCTION}

The kinetics of oxidation of cobalt (III) bound $\alpha$-hydroxy acids are important both from the mechanistic approach and its bearing on the mechanism of $\alpha$-hydroxy acid metabolism ${ }^{1,2}$. Several surfactants are able to aggregate in non-aqueous solvents to yield reverse micelles in which the polar head groups of the surfactant monomers group to form a micellar center and are directed towards the center of the gather, and the hydrophobic tails expand outwards into the bulk organic segment. A number of transition metal complexes have been used for studying electron transfer of different environments such as micelles., A large class of organic compounds was oxidized by Isoquinolinium Fluorochromate(IQFC) has been reported $^{5-7}$. Since induced electron transfer in pentaamminecobalt(III) complexes of $\alpha$-hydroxy acids with various oxidants have been studied. ${ }^{8-14}$ Induced electron transfer reactions in pentaamminecobalt(III) complexes of $\alpha$-hydroxy acids result in nearly $100 \%$ reduction at cobalt (III) center with synchronous $\mathrm{C}-\mathrm{C}$ bond fission and decarboxylation. Such an electron transfer path seems to be unavailable for Isoquinolinium Fluorochromate(IQFC) in its reaction with cobalt(III) bound and unbound $\alpha$ hydroxy acids to relevant keto acid, cobalt (III) complexes in Sodium Lauryl Sulfate (NaLS) $)^{15}$ and Cetyltrimethylammonium bromide $(\mathrm{CTAB})^{16,17}$ probably the transition state is more electron deficient. Such a transition state can be envisaged only when the $\mathrm{C}-\mathrm{H}$ bond fission occurs in the slow step with

Rasayan J. Chem., 12(3), 1127-1134(2019)

http://dx.doi.org/10.31788/RJC.2019.1235318

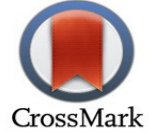


hydride ion transfer. The rate of IQFC oxidation of cobalt(III) complexes of $\alpha$-hydroxy acids depends on the first power of IQFC concentration. The 1 mole of $\mathrm{Co}$ (III) complexes of $\alpha$-hydroxy acids consumes 0.5 mole of Isoquinolinium Fluorochromate(IQFC), while 1 mole of unbound $\alpha$-hydroxy acids consume 1.0 mole of Isoquinolinium Fluorochromate(IQFC) correspondingly.

\section{EXPERIMENTAL}

\section{Materials and Methods}

\section{Preparation of Carbonatopentaammine cobalt(III) Nitrate}

Carbonatopentaamminecobalt(III) nitrate was prepared by dissolving $0.21 \mathrm{~mol}$ of powdered ammonium carbonato in $60 \mathrm{~mL}$ of water and $100 \mathrm{~mL}$ of concentration aqueous ammonia, adding a solution of 0.10 mol of cobalt (II) nitrate. 6 hydrate in $40 \mathrm{~mL}$ of water and then bubbling air very slowly through the mixture (20 bubbles/min.) for 20 days. The solution was cooled to $0^{\circ} \mathrm{C}$ and $600 \mathrm{~mL}$ of methanol was added slowly with stirring. The preparation was set aside at $0^{0} \mathrm{C}$ for 3 days, and the precipitated carbonato nitrate was filtered off. This was purified by dissolving in twice its weight of water, adding $\mathrm{LiCl}$ ( $1 \mathrm{~g}$ of $\mathrm{LiCl} / 2 \mathrm{~g}$ of the complex), filtering and then slowly adding an equal volume of methanol. The solution was kept $0^{0} \mathrm{C}$ for $10 \mathrm{hr}$ and the crystalline complex was filtered off and dried in vacuum ${ }^{18}$.

\section{Preparation of Pentaaminecobalt(III) Complexes of $\alpha$-Hydroxy Acids}

The monomeric cobalt(III) complexes of mandelic acid, lactic acid and malic acids ${ }^{19}$ were prepared as their perchlorates following the method of Fan $^{20}$ and Gould. ${ }^{15}$

$0.01 \mathrm{~mol}$ of the $\alpha$-hydroxy acids were dissolved in $20 \mathrm{ml}$ of methanol taken in a $50 \mathrm{ml}$ of R.B.flask and a pellet $(0.50$ to $1.00 \mathrm{~g}$ ) of $\mathrm{NaOH}$ was added. About $0.001 \mathrm{~mol}$ of finely powdered carbanatopentaammine cobalt(III) nitrate was added and the mixture was refluxed at $70^{\circ} \mathrm{C}$ for 2 hours. It was then cooled under the ice for 30 minutes; about $3 \mathrm{ml}$ of $70 \%$ perchloric acid was added drop wise while shaking the mixture was cooled again under the ice for 1 hour. The cobalt(III) complex precipitated as perchlorate and was filtered through a sintered glass crucible, washed well with ethanol followed by diethyl ether, dried and conserved in a desiccator.

\section{Preparation of Isoquinolinium Fluorochromate}

$\mathrm{Cr}(\mathrm{VI})$ oxide $(15.0 \mathrm{~g}, 0.15 \mathrm{~mol})$ is dissolved in water $(25 \mathrm{ml})$ in a polythene beaker and $40 \%$ hydrofluoric acid $(11.25 \mathrm{ml}, 0.225 \mathrm{~mol})$ is added with stirring at room temperature. To the ensuing clear orange solution, isoquinoline $(17.75 \mathrm{ml}, 0.15 \mathrm{~mol})$ is added dropwise with stirring. The mixture is heated on a water bath for about 15 minutes then cooled to room temperature, and allowed to set for 40-45 minutes. The bright orange, crystalline Isoquinolinium Fluorochromate is isolated by filtration in Buchner funnel. It is recrystallized using hot water and dried in vacuums for about one hour. ${ }^{21}$

\section{Kinetic Method}

All the glass apparatus were made of Pyrex glass and stoppers were well ground. The loss of solvent, tested in a standard flask and in reaction bottles, was found to be insignificant. Burettes, pipettes and standard flasks were consistent by usual method. ${ }^{22,23}$

\section{Rate Measurement}

The Isoquinolinium Fluorochromate oxidant of $\mathrm{Co}$ (III) complexes of $\alpha$-hydroxy acids and unbound ligand, the rate of measurements were made at $31 \pm 0.2^{0} \mathrm{C}$ in $100 \%$ aqueous medium. ${ }^{24}$ The standard solution prepared and required amount solutions were pipette out into a $1 \mathrm{~cm}$ cell. The total volume of the reaction mixture in the spectrophotometer cell was kept as $2.5 \mathrm{~mL}$ in each kinetic run. A UVVisible spectrophotometer was used to follow the rate of the reaction. Rates of this unbound ligand and $\mathrm{Co}$ (III) bound complexes were computed from the observed decrease in absorbance at $350 \mathrm{~nm}$. For all the kinetic experiments, the conversion was followed at least for four half-lives and specific rates from successive half-lives fixed with + or $7 \%$ and the average values did not differ from a plot of logarithmic change in concentration versus time computed using integrated rate equation. ${ }^{25}$ 


\section{Stoichiometric Studies}

The stoichiometric studies for the Isoquinolinium Fluorochromate(IQFC) oxidation of pentaamminecobalt(III) complexes of $\alpha$-hydroxy acids and unbound ligands in the presence of micelles Table-1 were carried out with the oxidant in excess. The $\left[\mathrm{H}^{+}\right]$and ionic strength were maintained as in the corresponding rate measurements. The temperature was carried out at $31 \pm 0.2^{\circ} \mathrm{C}$. After 100 hours when the reaction was nearing completion, the concentration of unreacted IQFC was determined both iodometrically and spectrophotometrically from the change in absorbance measured at $350 \mathrm{~nm}$. Likewise, the stoichiometric studies for the IQFC oxidation of pentaamminecobalt(III) complexes of $\alpha$ hydroxy acids and unbound ligands in the presence of micelles were carried out. ${ }^{26,27}$

Table-1: Stoichiometric Data for IQFC Oxidation of Co(III) bound and unbound $\alpha$-hydroxy acids in the presence of NaLS \& CTAB

\begin{tabular}{|c|c|c|c|c|}
\hline $\begin{array}{c}10^{3}[\text { Compound }] \\
\mathrm{mol} \mathrm{dm}^{-3}\end{array}$ & $\begin{array}{c}10^{2}[\mathrm{IQFC}] \\
\text { Initial } \\
\mathrm{mol} \mathrm{dm}^{-3}\end{array}$ & $\begin{array}{c}10^{2}[\mathrm{IQFC}] \\
\text { Final } \\
\mathrm{mol} \mathrm{dm}^{-3}\end{array}$ & $\begin{array}{c}\Delta 10^{3}[\mathrm{IQFC}] \\
\mathrm{mol} \mathrm{dm}^{-3}\end{array}$ & $\begin{array}{c}\text { [Compound]: } \\
\Delta[\text { IQFC] }\end{array}$ \\
\hline $\begin{array}{c}\text { Mandelic acid } \\
1.0 \\
2.0 \\
4.0 \\
\text { Lactic acid } \\
1.0 \\
2.0 \\
4.0 \\
\text { Malic acid } \\
1.0 \\
2.0 \\
4.0 \\
\text { Mandelato } \\
1.0 \\
2.0 \\
4.0 \\
\text { Lactato } \\
1.0 \\
2.0 \\
4.0 \\
\text { Malato } \\
1.0 \\
2.0 \\
4.0 \\
\end{array}$ & $\begin{array}{l}1.0 \\
2.0 \\
2.0 \\
1.0 \\
2.0 \\
2.0 \\
\\
1.0 \\
2.0 \\
2.0 \\
\\
1.0 \\
2.0 \\
2.0 \\
\\
1.0 \\
2.0 \\
2.0 \\
1.0 \\
2.0 \\
2.0\end{array}$ & $\begin{array}{l}0.89 \\
1.80 \\
1.60 \\
\\
0.90 \\
1.81 \\
1.60\end{array}$ & $\begin{array}{l}1.20 \\
2.20 \\
4.30 \\
\\
0.50 \\
1.10 \\
2.01 \\
\\
0.49 \\
1.00 \\
2.00 \\
\\
0.50 \\
1.20 \\
2.02\end{array}$ & $\begin{array}{l}1.00: 1.10 \\
1.00: 1.00 \\
1.00: 1.00 \\
1.00: 1.00 \\
1.00: 0.95 \\
1.00: 1.00 \\
1.00: 1.20 \\
1.00: 1.10 \\
1.00: 1.07 \\
\\
2.00: 1.00 \\
2.00: 1.10 \\
2.00: 1.00 \\
\\
2.00: 0.98 \\
2.00: 1.00 \\
2.00: 1.00\end{array}$ \\
\hline
\end{tabular}

\section{RESULTS AND DISCUSSION}

Dependence of Rate on Isoquinolinium Fluorochromate(IQFC) Oxidation Cobalt(III) Complexes of $\alpha$-hydroxy Acids in Micellar Medium

The rate of Isoquinolinium Fluorochromate(IQFC) oxidation of pentaamminecobalt(III) complexes of $\alpha$ hydroxy acids had been followed under pseudo-first order condition by maintaining an excess of the complex concentration than the reagent. The rate constants were calculated by the integrated rate equation. The graph of the logarithm of concentration versus time was linear and the rate constants calculated from the slope of the graph agreed with the experimental value, which shows first-order dependence on $\left.[(\mathrm{NH} 3) 5 \mathrm{Co}(\mathrm{III})-\mathrm{L}]^{2+}\right]$ Table-2, (Fig.-1). This was further substantiated from the study of 
varying the concentration of pentaamminecobalt(III) complexes of $\alpha$-hydroxy acids from [0.5 to 2.5] X $10^{2} \mathrm{~mol} \mathrm{dm}^{-3}$ at a fixed concentration in the micellar medium. The rate constants obtained for the different concentration of $\left.[(\mathrm{NH} 3) 5 \mathrm{Co}(\mathrm{III})-\mathrm{L}]^{2+}\right]$ complexes of $\alpha$-hydroxy acids were nearly a constant. Hence the rate of disappearance of complexes in this concentration range studied is given as Table-3, (Fig.-2 and 3).

$$
\left.\left.-\mathrm{d}[(\mathrm{NH} 3) 5 \mathrm{Co}(\mathrm{III})-\mathrm{L}]^{2+}\right] / \mathrm{dt}=\mathrm{k} 1[(\mathrm{NH} 3) 5 \mathrm{Co}(\mathrm{III})-\mathrm{L}]^{2+}\right]
$$

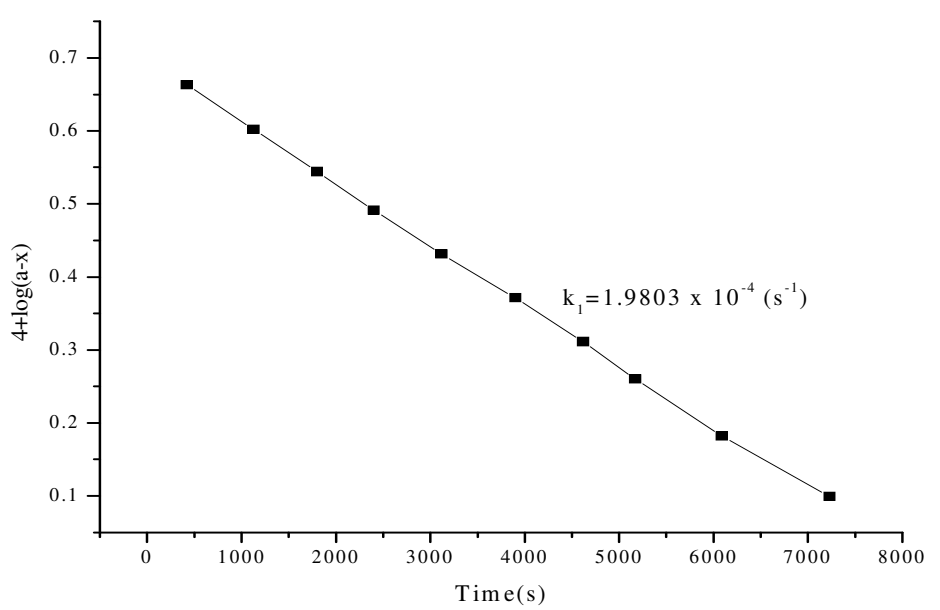

Fig.-1: First Order Dependence Plot

Table-2: First Order Rate on IQFC Oxidation of Pentaamminecobalt(III) Complexes $[\mathrm{IQFC}]=1.25 \mathrm{~mol} \mathrm{dm}^{-3}, \mathrm{H}_{2} \mathrm{SO}_{4}=0.5 \mathrm{~mol} \mathrm{dm}^{-3}$, Temperature $=31 \pm 0.2^{\circ} \mathrm{C}, \mathrm{L}=$ Mandelic Acid

\begin{tabular}{c|c|c}
\hline Time (s) & $\begin{array}{c}\log (\mathrm{a}-\mathrm{x}) \\
\mathrm{mol} \mathrm{dm}\end{array}$ & $\begin{array}{c}10^{4} \mathrm{k}_{1} \\
\left(\mathrm{~s}^{-1}\right)\end{array}$ \\
\hline 300 & 0.662 & 2.461 \\
600 & 0.632 & 2.464 \\
900 & 0.603 & 2.463 \\
1200 & 0.574 & 2.471 \\
1500 & 0.545 & 2.464 \\
1800 & 0.516 & 2.459 \\
2100 & 0.487 & 2.457 \\
2400 & 0.458 & 2.461 \\
2700 & 0.429 & 2.463 \\
3000 & 0.401 & 2.461 \\
\hline
\end{tabular}

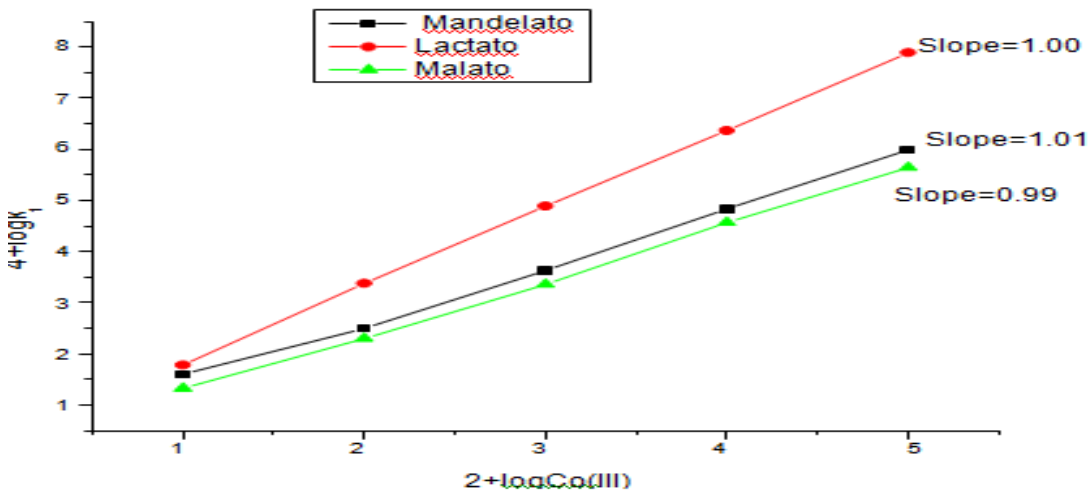

Fig--2 Dependence of rate on $[\mathrm{Co}(\mathrm{III})]$ in NaIS 
RASĀYAN J. Chem.

Vol. 12 | No. 3 |1127 - 1134| July - September | 2019

Table-3: Dependence of Rate on IQFC Oxidation Cobalt(III) Complexes of $\alpha$-Hydroxy Acids in Micellar Medium $\left.\left[\left(\mathrm{NH}_{3}\right)_{5} \mathrm{Co}(\mathrm{III})-\mathrm{L}\right]^{2+}\right]=1.25 \mathrm{~mol} \mathrm{dm}^{-3}, \mathrm{H}_{2} \mathrm{SO}_{4}=0.5 \mathrm{~mol} \mathrm{dm}^{-3},[\mathrm{NaLS}]=1.00 \mathrm{X} 10^{3} \mathrm{~mol} \mathrm{dm}^{-3},[\mathrm{CTAB}]=1.00 \mathrm{X} 10^{3}$ mol dm ${ }^{-3}$, Temperature $=31 \pm 0.2^{\circ} \mathrm{C}$

\begin{tabular}{|c|c|c|c|c|}
\hline \multirow{2}{*}{$\begin{array}{c}10^{2}\left[\left(\mathrm{NH}_{3}\right)_{5} \mathrm{Co}(\mathrm{III})\right. \\
-\mathrm{L}] \mathrm{mol} \mathrm{dm}^{-3}\end{array}$} & \multicolumn{2}{|c|}{ NaLS } & \multicolumn{2}{|c|}{ CTAB } \\
\hline & $\begin{array}{c}10^{4} \mathrm{k}_{1} \\
\left(\mathrm{~s}^{-1}\right)\end{array}$ & $\begin{array}{c}10^{2} \mathrm{k}_{2} \mathrm{dm}^{3} \\
\mathrm{~mol} \mathrm{~s}^{-1}\end{array}$ & $\begin{array}{c}10^{4} \mathrm{k}_{1} \\
\left(\mathrm{~s}^{-1}\right)\end{array}$ & $\begin{array}{c}10^{2} \mathrm{k}_{2} \mathrm{dm}^{3} \\
\mathrm{~mol} \mathrm{~s}^{-1} \mathrm{~s}\end{array}$ \\
\hline \multicolumn{5}{|l|}{ Mandelato } \\
\hline 0.5 & 1.204 & 1.368 & 1.567 & 1.678 \\
\hline 1.0 & 2.498 & 2.567 & 3.089 & 3.189 \\
\hline 1.5 & 3.631 & 3.563 & 4.567 & 4.609 \\
\hline 2.0 & 4.834 & 4.987 & 6.024 & 6.193 \\
\hline 2.5 & 5.990 & 5.891 & 7.498 & 7.590 \\
\hline \multicolumn{5}{|l|}{ Lactato } \\
\hline 0.5 & 1.783 & 1.670 & 1.906 & 1.897 \\
\hline 1.0 & 3.378 & 3.276 & 3.859 & 3.894 \\
\hline 1.5 & 4.890 & 4.906 & 5.794 & 5.367 \\
\hline 2.0 & 6.368 & 6.287 & 7.637 & 6.736 \\
\hline 2.5 & 7.891 & 7.704 & 9.521 & 8.209 \\
\hline \multicolumn{5}{|l|}{ Malato } \\
\hline 0.5 & 1.126 & 1.283 & 1.367 & 1.490 \\
\hline 1.0 & 2.298 & 2.325 & 2.599 & 2.678 \\
\hline 1.5 & 3.357 & 3.206 & 3.814 & 3.908 \\
\hline 2.0 & 4.567 & 4.987 & 5.203 & 5.199 \\
\hline 2.5 & 5.641 & 5.418 & 6.408 & 6.000 \\
\hline
\end{tabular}

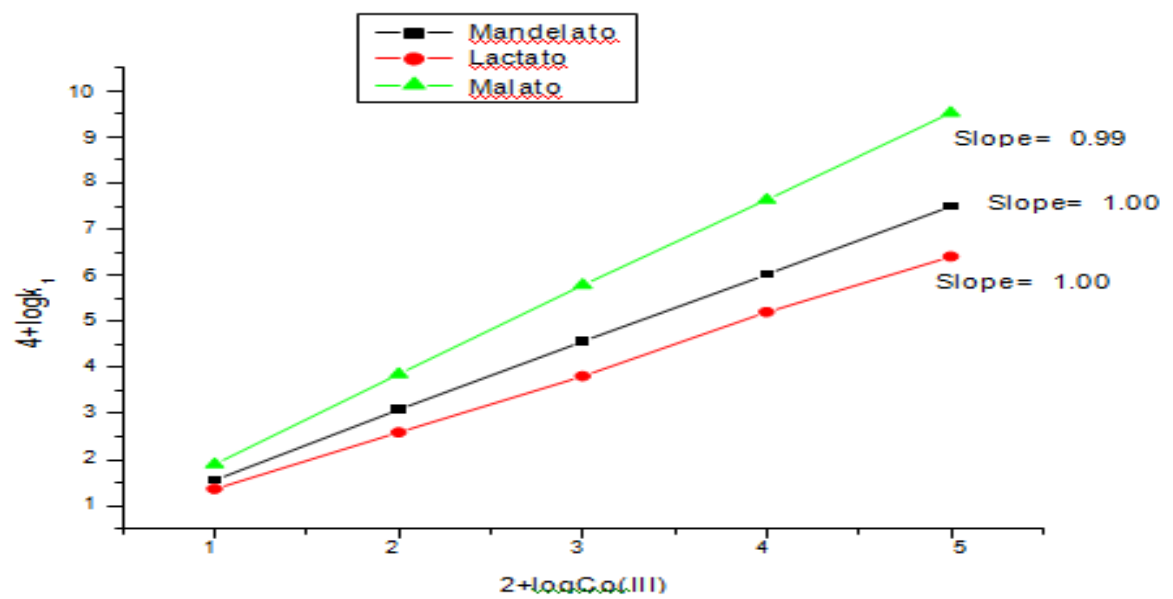

Fig.-3 Dependence of rate on [Co(III)] in CTAB

Table-4: Activation parameters and second order rate constants for the oxidation of $\left[\left(\mathrm{NH}_{3}\right)_{5} \mathrm{Co}(\mathrm{III})-\mathrm{L}\right]^{2+}$ by IQFC $\left.\left[\left(\mathrm{NH}_{3}\right)_{5} \mathrm{Co}(\mathrm{III})-\mathrm{L}\right]^{2+}\right]=1.25 \mathrm{~mol} \mathrm{dm}^{-3} ;[\mathrm{IQFC}]=1.25 \mathrm{~mol} \mathrm{dm}^{-3} ;\left[\mathrm{H}_{2} \mathrm{SO}_{4}\right]=0.5 \mathrm{~mol} \mathrm{dm}^{-3}$

\begin{tabular}{c|c|c|c}
\hline Parameters & $\begin{array}{c}\text { Lactato } \\
10^{4} \mathrm{k}_{1}\left(\mathrm{~s}^{-1}\right)\end{array}$ & $\begin{array}{c}\text { Mandelato } \\
10^{4} \mathrm{k}_{1}\left(\mathrm{~s}^{-1}\right)\end{array}$ & $\begin{array}{c}\text { Malato } \\
10^{4} \mathrm{k}_{1}\left(\mathrm{~s}^{-1}\right)\end{array}$ \\
\hline $\begin{array}{c}\text { TTemperature }] \\
298 \mathrm{~K}\end{array}$ & 1.31 & 1.07 & 3.11 \\
\hline
\end{tabular}


RASĀYAN J. Chem.

Vol. 12 | No. 3 |1127 - 1134| July - September | 2019

\begin{tabular}{c|c|c|c}
\hline $303 \mathrm{~K}$ & 1.71 & 1.57 & 3.62 \\
$308 \mathrm{~K}$ & 2.11 & 2.07 & 4.14 \\
$313 \mathrm{~K}$ & 2.51 & 2.58 & 4.65 \\
\hline [Activation & & & \\
parameters] & & & \\
$\mathrm{E}_{\mathrm{a} J \mathrm{KJol}^{-1}}$ & 25.08 & 20.49 & 59.55 \\
$\Delta \mathrm{H} \mathrm{KJmol}^{-1}$ & 22.56 & 17.97 & 57.03 \\
$-\Delta \mathrm{S} \mathrm{JK}^{-1} \mathrm{~mol}^{-1}$ & 120.16 & 115.57 & 154.63 \\
$\Delta \mathrm{G} \mathrm{KJmol}^{-1}$ & 59.81 & 53.79 & 104.96 \\
& & & \\
\hline
\end{tabular}

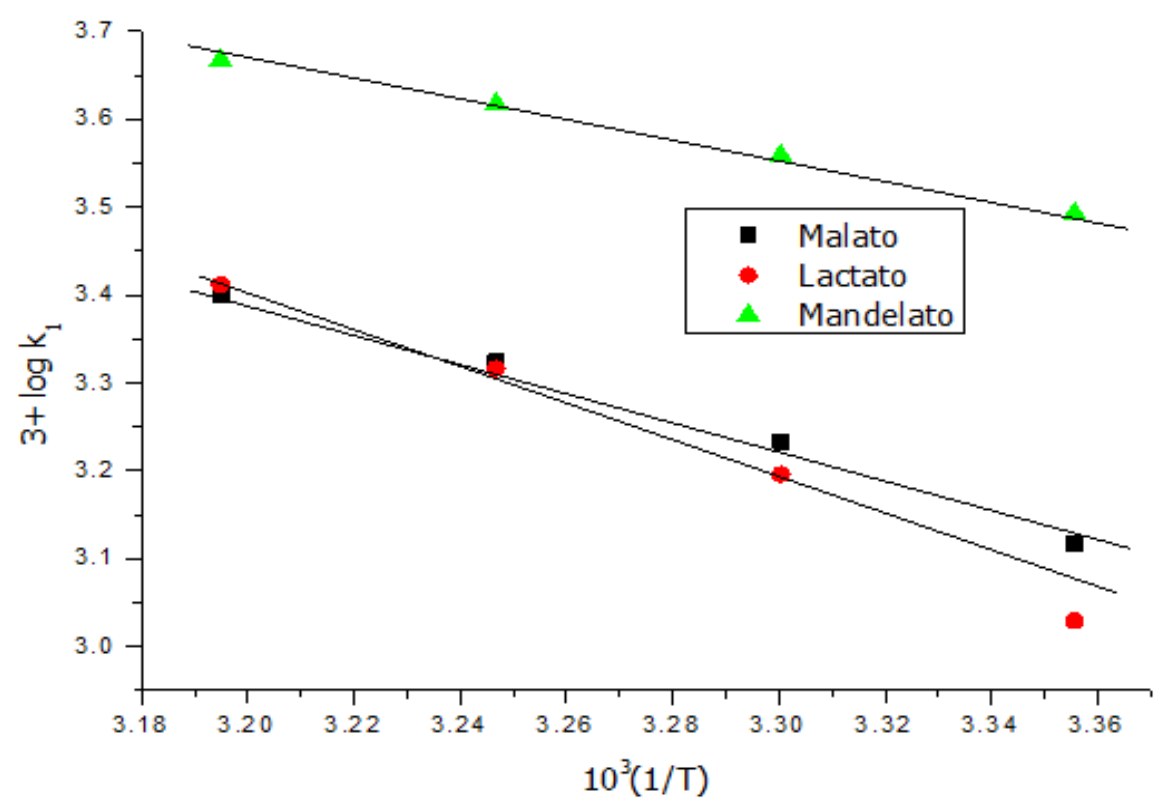

Fig.-4 Dependence of rate on [Co(III)] at various temperatures

All the kinetic runs were repetitive and the rate constants were reproducible within $\pm 2 \%$ range.

\section{Effect of Varying the Temperature of Cobalt(III) Complexes of $\alpha$-hydroxy Acids}

The effect of varying the temperature on the rate of IQFC oxidation of pentaamminecobalt(III) complexes $\alpha$-hydroxy acids has been investigated in the range of temperatures $25^{\circ} \mathrm{C}$ to $40^{\circ} \mathrm{C} \pm 0.2^{\circ} \mathrm{C}$ which was given in Table- 4 With rising the temperature, an increase in the rate is observed. A graph of $\operatorname{logk} \mathrm{k}_{1}$ versus temperature [1/T] is a linear (Fig.-4). At a higher temperature of $\alpha$-hydroxy acids, the nearly maximum rate has been observed. The linear pattern of the curve of these catalyzed the oxidation. If the reaction species is ionic the reaction would have been accelerated and retarded in the other depending on the charge carried by it. Lower the value of Ea indicates that it is a better catalyst for the above oxidation reaction.

Mechanism of IQFC Oxidation of Pentaamminecobalt(III) Complexes of Both Bound and Unbound $\alpha$-Hydroxy Acids in Micellar Medium.

Isoquinolinium Fluorochromate(IQFC) oxidizes $\mathrm{OH}$ center of the $\alpha$-hydroxy acids at a rate of comparable to that of the free ligand. There is $100 \%$ reduction at the Proton center, forms an Isoquinolinium Fluorochromate ester which can decompose in a slow step, takings through $\mathrm{C}$-C bond fission leading to the formation of carbonyl compounds with the evolution of carbon dioxide and $\mathrm{H}_{2}$ gas. 
RASĀYAN J. Chem.

Vol. 12 | No. 3 |1127 - 1134| July - September | 2019

Considering these facts and findings with these results, the following reaction schemes have been projected for the IQFC oxidation of pentaamminecobalt(III) complexes of both bound and unbound $\alpha$-hydroxy acids.
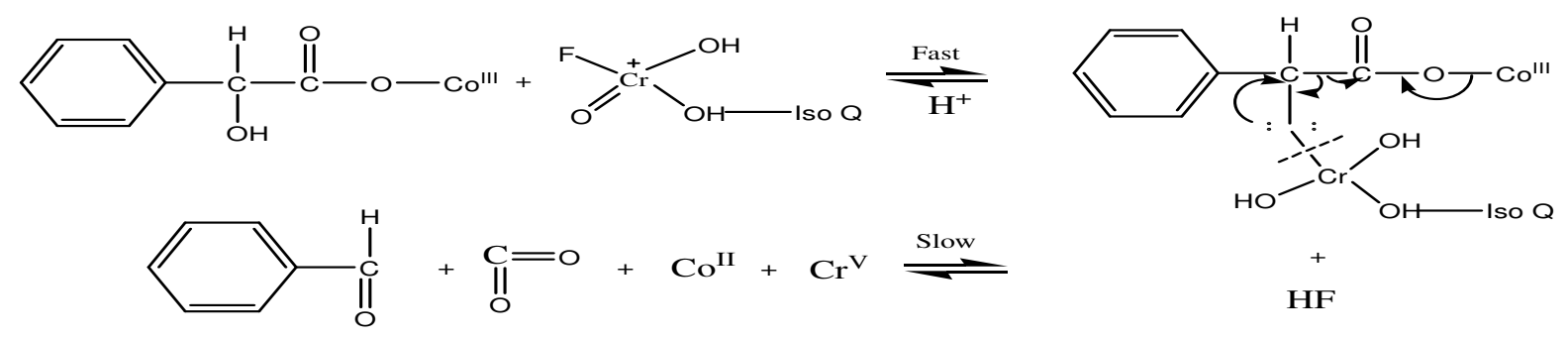

Scheme-1

\section{CONCLUSION}

An induced electron transfer reaction has been attempted presently with Isoquinolinium Fluorochromate(IQFC) and pentaamminecobalt(III) complexes of $\alpha$-hydroxy acids in the presence of NaLS \& CTAB medium. The reaction exhibits second order kinetics. In these reactions, the rate of oxidation shows first order kinetics. The reactions have followed by observing the decrease in the absorbance at $502 \mathrm{~nm}$ for Co(III) complex in a UV-visible spectrophotometer.

Product and Stoichiometric analysis were carried out for the oxidation of complexes and free ligands in two different (Anionic \& Cationic) micellar medium. with increasing micellar concentration an enhance in the rate is observed. IQFC oxidizes cobalt(III) bound and unbound $\alpha$-hydroxy acids through free radical. It explains the synchronous C-C bond fission, decarboxylation and electron transfer to cobalt(III) center. The added CTAB enhances the rate of oxidation of a reaction much more than NaLS. A mechanism involving the one-electron transfer for the complex and two electron transfer for the ligand was proposed i.e., the 1 mole of $\mathrm{Co}(\mathrm{III})$ complexes of $\alpha$-hydroxy acids consumes 0.5 mole of Isoquinolinium Fluorochromate, whereas 1 mole of unbound $\alpha$-hydroxy acids consume 1.0 mole of Isoquinolinium Fluorochromate(IQFC).

In the present work, on such a reaction with pentaamminecobalt(III) complexes of $\alpha$-hydroxy acids, the rate of disappearance of cobalt(III) is found to be almost the same as the rate of formation of cobalt(II) or the respective carbonyl product. The quantum yield of cobalt (III) obtained is nearly 100\% for all these complexes. Nearly $100 \%$ reduction at cobalt (III) center, with the formation of $100 \%$ of cobalt (II) and respective carbonyl product is briefed by a metal-centered excitation resulting in a metal-ligand bond breaking accompanied by $\mathrm{d} \rightarrow \pi$ back bonding to ligand, facilitating carbon-carbon fission, possibly in a synchronous manner. When a mixture of pentaamminecobalt(III) complexes of $\alpha$-hydroxy acids with acrylonitrile is irradiated with $254 \mathrm{~nm}$, as polymerization does not found, the reduction of this complex, possibly, does not produce long-lived organic radical. The reaction goes by free radical mechanism was proved by acrylonitrile polymerization. The appropriate methodology has been adopted.

\section{ACKNOWLEDGMENT}

The author wishes to thank Principal Dr. P. Natarajan, Priyadarshini Engineering College, Vaniyambadi, TamilNadu, India. I express my sincere thanks to my Guide Dr.K.Subramani, PG \& Research Department of Chemistry, Islamiah College, Vaniyambadi, for providing me an opportunity for completing research work fruitfully.

\section{REFERENCES}

1. P. K . Sharma, Int. J. Chem. Kinet. 38, 364 (2006), DOI: 10.1002/kin.20466, Nov 2009. 
RASĀYAN J. Chem.

Vol. 12 | No. 3 |1127 - 1134| July - September | 2019

2. M. L. Bishnoi, S. C. Negi and K. K. Banerji, Indian J. Chem., 25A, 660 (1986), DOI: 10.1007/BF03245962.

3. Tapas Majumdar and Ambikesh Mahapatra, Indian J. Chem., 46A, 952 (2007).

4. M. A. Malik and Z. Khan, Colloids Surf B: Biointerfaces, 72, 253(2009), DOI: 10.1016/j.colsurfb.2009.04.012.EPub2009 Apr19.

5. S. Srinivasan, J. Annaraj and P. R. Attappan, J. Inorg. Biochem., 99, 876 (2005).

6. L. L. Scramm, E. N. Stasiuk, D. G. Marangoni, and Annu, Rep. Prog. Chem. Sect. 3, 99 (2003).

7. M. J. Rosen, Surfactants and Interfacial Phenomenon, $3^{\text {rd }}$ Edn. Wiley, New Jersey, 569 (2004).

8. V. Dhariwal, D. Yajurvedi and P. K. Sharma, Indian J. Chem., 45A, 1158 (2006).

9. S. S. Mansoor, Asian J. Chem., 22(10), 7591(2010).

10. P. Sundararaman, and W. Herz, J. Org. Chem., 42, 813 (1977), DOI: 10.1021/jo00425a009

11. E. Santaniello and P. Ferraboschi, Synth. Commun. 10, 75 (1980).

12. J. M. S. Frechet, D. Pauline and J. Farad, J. Org. Chem., 46, 1728 (1981).

13. F. S. Guizec and F. A. Luzzio, Synthesis, 691 (1980).

14. D. Preeti Swami, P. Yajurvedi, Mishra and Pradeep, K. Sharma, Int. J. Chem. Kinet., 42, 50 (2010).

15. E. S. Gould and H. Taube, J Am Chem Soc., 86, 1318 (1964), DOI: 10.1021/ja01061a012.

16. D. Sarkar, K. C. Khilar, G. Begum and P. V. Subharao Coll Surf. 268A, 73 (2005).

17. D. Sarkar, P. V. Subharao, G. Begum and K. Ramakrishnan, J. Coll. Interf Sci., 288, 591 (2005).

18. S. Sheik Mansoor, V. Saleem Malik, K. Aswin, K. Logaiya and A. M. Hussain, Journal of Saudi Chemical Society (2012)

19. E. S. Amis, Solvent effects on reaction rates \& mechanism (Academic Press, New York) (1966).

20. F. R. F. Fan and E.S.Gould, Inorg. Chem., 13, 2639 (1974).

21. R. Srinivasan, K. Balasubramanian and Preethi Stanley, Synthetic Communications, 27(12), 2057 (1997).

22. T. M. Puttaswamy, Anuradha and K.L.Mahadevappa, Indian J Chem., 40A, 514 (2001). I

23. M. K. Mishra, Rasayan J. Chemistry,11(4), 1393-1398 (2018), DOI:10.31788/RJC.2018.1143056.

24. N. Vijai, D. Mala, C. L. Khandelwal and P. D. Sharma, Indian J Chem., 47A, 859 (2008).

25. Santhosh Kumar and O. D. Gupta, Rasayan J. Chem., 3(3), 581(2010).

26. A. Ahmed, Abdel-Khalek, Eman. S. Hassan and Hala M.Hassan, Indian J. Chem. Technol. 14, 466 (2007).

27. D. V. Prabhu and Chetana Rana, Rasayan J. Chemistry, 11(3), 1084(2018), DOI: 10.31788/RJC.2018.1131862.

[RJC-5318/2019] 